\title{
FAK Family Tyrosine Kinase
}

National Cancer Institute

\section{Source}

National Cancer Institute. FAK Family Tyrosine Kinase. NCI Thesaurus. Code C20037.

Soluble cytoplasmic non-receptor FAK (Focal Adhesion Kinase) Family Tyrosine Kinases catalyze the phosphorylation of tyrosine residues in proteins with ATP or other nucleotides as phosphate donors. FAK is found in intracellular signaling focal adhesion complexes following eng agement of the extracellular matrix by integrins. The C-terminal 'focal adhesion targeting' (FAT) region is necessary and sufficient for localizing FAK to focal adhesions. 